\title{
Sorghum Farmers' Climate Change Adaptation Strategies in the Semiarid Region of Cameroon
}

\author{
Salé Abou, Madi Ali, Anselme Wakponou, and Armel Sambo
}

\section{Contents}

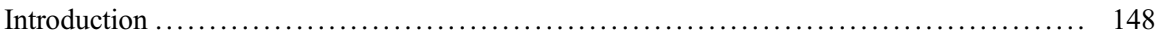

Socioeconomic Characteristics of the Sorghum Farmers ........................... 149

Climate Hazards and Sorghum Farmers' Adaptation Strategies ........................ 149

Sahelian Farmers Adaptation Strategies' Typologies ............................... 153

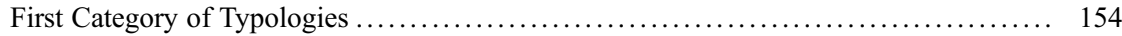

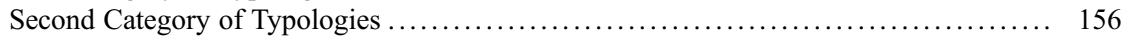

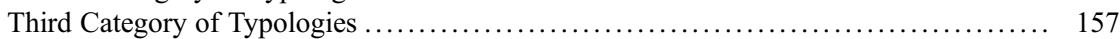

Characterization of Sorghum Farmers' Adaptation Strategies ....................... 157

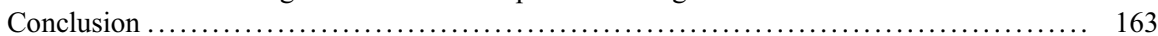

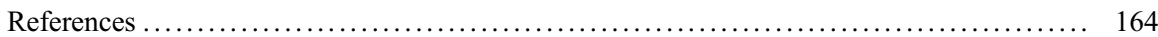

\section{Abstract}

This chapter deals with the problem of sorghum farmers' adaptation to climate change in the semiarid region of Cameroon. Its general objective is to compare the various adaptation strategies' typologies and to characterize the sorghum farmers' adaptation strategies on the basis of the suitable one. The stratified

This chapter was previously published non-open access with exclusive rights reserved by the Publisher. It has been changed retrospectively to open access under a CC BY 4.0 license and the copyright holder is "The Author(s)". For further details, please see the license information at the end of the chapter.

\section{S. Abou $(\bowtie) \cdot$ M. Ali}

National Advanced School of Engineering of Maroua (ENSPM), The University of Maroua, Maroua, Cameroon

\section{A. Wakponou}

Faculty of Arts, Letters and Human Sciences (FALSH), The University of Ngaoundéré, Ngaoundéré, Cameroon

\footnotetext{
A. Sambo

Faculty of Arts, Letters and Human Sciences (FALSH), The University of Maroua, Maroua, Cameroon
} 
random sampling method was used to select the sites, which consist of twenty (20) villages, and the sample, which consists of six hundred (600) farm household heads. After conducting focus-groups in ten villages and interviews with resource persons, the primary data were collected using a semi-open survey questionnaire. It appears that the poor spatiotemporal distribution of rains and the drought constitute, respectively, the main climate hazard and the main water risk that farmers are dealing with; the farmers are vulnerable to climate change because the adaptation strategies used are mostly traditional, their adoption rates are very low, and the use of efficient adaptation strategies (irrigation, improved crop varieties) is almost unknown. The characterization of the adaptation strategies used shows that they are more complex than most authors who have established the typologies thought. It comes out that improving the resilience of these sorghum farmers absolutely requires the improvement of their basic socioeconomic conditions.

\section{Keywords}

Semiarid region $\cdot$ Sorghum farmers $\cdot$ Climate change $\cdot$ Climate hazard $\cdot$ Water risk $\cdot$ Adaptation strategies

\section{Introduction}

Farmers in the semiarid regions of Africa, to which belongs the Diamare division in the Far North Cameroon, are among the most vulnerable to water constraints caused by climate variability during the 1960 s and 1970 s. This vulnerability has its origin in their essentially rain-fed agriculture, their unfavorable socioeconomic characteristics, and their very fragile ecosystem.

According to Borton and Nicholds (1994), of all-natural hazards, droughts are the ones with the greatest economic impact, and affecting the greatest number of people. In the Diamare division, as in the whole semiarid zone of Cameroon, water constraints, particularly droughts and floods, have had a negative impact on cereals' production, especially sorghums, which constitute the basic food of the population. According to L'hôte (2000), the period called "Drought in the Sahel" was an agronomic disaster for the entire region. Similarly, the results of the simulations carried out by Blanc (2012), compared to a reference without climate change, indicate that sorghum yields could decrease by around $-47 \%$ to $-7 \%$ by 2,100 in this region. Faced with this situation, a wide variety of adaptation strategies emanating from both farmers and agricultural research has been made available to sorghum farmers, but adoption rate remains low as everywhere else in the African semiarid zones (Yesuf et al. 2008; Leary Kulkarmi and Seipt 2007).

In order to better understand the main orientations of these various adaptation strategies, a variety of typologies has been previously established by some authors (Dingkuhn 2009; Nhemachena and Hassan 2007; Jouve 2010; then Fabre 2010); but a comparison between adaptation strategies on the basis of these typologies remains difficult because of the diversity of analysis' angles used by the authors. For this reason, it seems better to identify the main similarities and differences between the 
various typologies, and then to characterize the sorghum farmers' adaptation strategies on the basis of the most suitable typology. The sorghum farmers' adaptation strategies' characterization could allow researchers as well as policy-makers to better reorient research priorities and policies in order to improve farmers' resilience.

The Diamare division located in the Far-North region of Cameroon (Fig. 1), between $10^{\circ}$ and $11^{\circ}$ North latitude $\left(10^{\circ} 30^{\prime} 00^{\prime \prime}\right)$ and $14^{\circ}$ and $15^{\circ}$ East longitude $\left(14^{\circ}\right.$ $\left.30^{\prime} 00^{\prime \prime}\right)$, constituted the focus area. The climate is Sudano-Sahelian in its southern part and Sahelo-Sudanian in its northern part, all characterized by a long dry season (7-9 months), and a short rainy season. Agriculture (rainy season, dry season), animal husbandry, fishing, trade, and crafts are the main activities of these populations.

The information has been collected through directed interviews with some resource people (researchers, patriarchs, heads of technical services), and then focus groups and a survey questionnaire submitted to six hundred (600) household heads. The descriptive and inferential statistics (frequencies, percentages, Principal Component Analysis, Kaiser-Meyer-Olkin/KMO test) from the SPSS statistical software have been used to analyze the information gathered.

\section{Socioeconomic Characteristics of the Sorghum Farmers}

In general, agriculture and livestock are the main activities of the farmers, and the Diamare division is one of the three divisions most exposed to food insecurity in the region. Priority is given to cereals in terms of land mobilization and work (CEDC 2010), and sorghum (rainy and dry seasons) constitute the staple food of the populations. This agriculture is essentially characterized by the practice of polyculture $(93.80 \%)$ and self-consumption agriculture $(79 \%)$, the small size of the sown areas $(100 \%<10$ ha, with areas varying between 0,5 ha and 1 ha for sorghum), the low quantity of agricultural inputs used (FAO 2009), the poor access to agricultural supervision $(51.50 \%)$, and to credits $(43.50 \%)$. Cotton and onion are the only export crops. In order to ensure their daily survival, these farmers multiply income-generating activities $(65.50 \%)$, which reflects the inability of agricultural activities to meet their food needs, and therefore their high vulnerability. The household heads are mostly men, most of them aged between 35 and 54 years (FAO 2009), with an average age of 48 years in Diamaré. The average household size is around 9 people, and seems to be high compared to a regional average of 7 and a national average of 5.7. The school enrollment rate, which is $57 \%$, is the lowest in the country, with $39.30 \%$ having reached primary, $17 \%$ secondary, and less than $1 \%(0.4 \%)$ higher education. Health and school infrastructures are among the least fortunate in the country.

\section{Climate Hazards and Sorghum Farmers' Adaptation Strategies}

Table 1 summarizes the climate hazards imposed by the climate change to the rainy and dry seasons' sorghum production. 


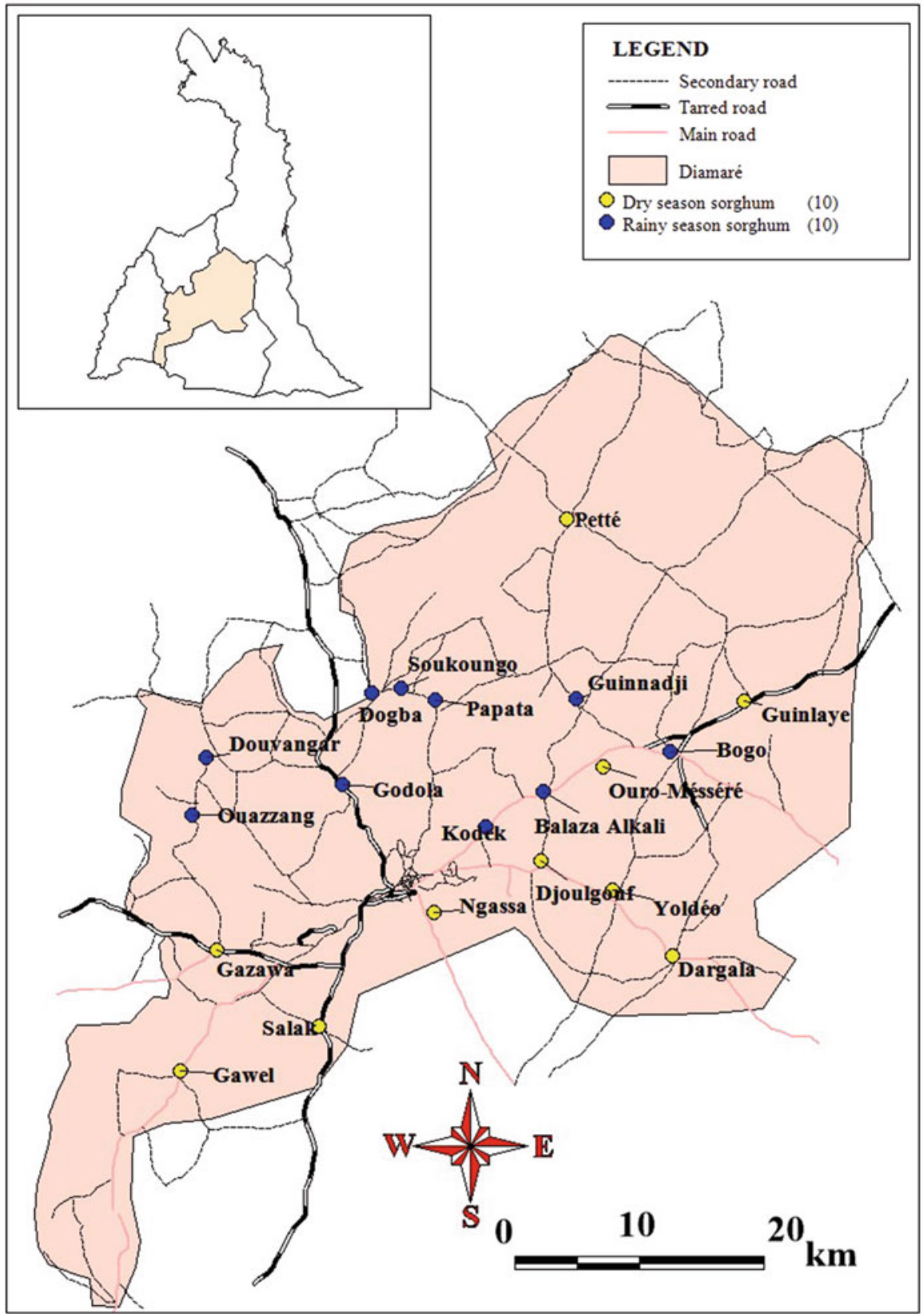

Fig. 1 The Diamaré division in the Far-north region of Cameroon 
Table 1 Climate hazards perceived by rainy and dry seasons sorghums' farmers

\begin{tabular}{|c|c|c|c|c|}
\hline \multirow[b]{2}{*}{ Climate hazards } & \multicolumn{2}{|c|}{$\begin{array}{l}\text { Rainy season } \\
\text { sorghum }\end{array}$} & \multicolumn{2}{|c|}{$\begin{array}{l}\text { Dry season } \\
\text { sorghum }\end{array}$} \\
\hline & Total & $\%$ & Total & $\%$ \\
\hline Late or early arrival of rains & 300 & 100 & 297 & 99 \\
\hline Early cessation of rains & 300 & 100 & 293 & 97,67 \\
\hline Poor spatial rainfall distribution & 299 & 99,67 & 299 & 99,67 \\
\hline More frequent and long dry spells & 300 & 100 & 300 & 100 \\
\hline Flooding of crops & 300 & 100 & 294 & 98 \\
\hline General decline in the total amount of rainfall & 299 & 99,67 & 296 & 98,67 \\
\hline Rapid drying of water sources (ponds, rivers, lakes, wells) & - & - & 300 & 100 \\
\hline Rapid drying and hardening of soils & - & - & 292 & 97,33 \\
\hline Light rains at the beginning of the rainy season & - & - & 297 & 99 \\
\hline Absence of heavy rains at the end of the rainy season & - & - & 297 & 99 \\
\hline No haze during cold season & - & - & 299 & 99,67 \\
\hline
\end{tabular}

Most of the climate hazards listed relate to the poor spatiotemporal distribution of rains, while most of them are linked to drought, and not to excess water (floods); that means the poor spatiotemporal distribution of rains is the main climate hazard while drought is the main water risk limiting agricultural production both during the rainy and dry seasons in the area. This observation confirms the results obtained by Chédé (2012), Gnanglé et al. (2012), then Agossou et al. (2012).

Likewise, it emerges that all the three known forms of drought are represented here:

- Meteorological drought (late arrival of the rains, early start of the rains, dry spells, decrease in the amount of rains, light rains at the start of the rainy season, light rains at the end of the rainy season)

- Agricultural drought (rapid drying and hardening of soils)

- Hydrological drought (rapid drying up of ponds and rivers)

According to FAO and National Drought Mitigation Center (2008), when all of these three forms of drought rage somewhere, automatically, the socioeconomic drought which is their logical consequence, will also rage there; and that is noticeable through the socioeconomic characteristics of the sorghum farmers described in the previous paragraph.

One can also remark the high rate of climate hazards' perception by the farmers, which could reflect both the extent and the severity of these constraints, but also a good perception of the phenomena by farmers who control their physical environment. Indeed, Arodokoun (2011) considers that, in general, peasant communities which maintain close links with their environment have a perfect knowledge of the climate, its manifestations and the changes that have occurred. This situation could 
also be justified by the fact that according to Nhemachena and Hassan (2007), climate change has very negative effects on the poorest households which have the least capacity to adapt to changing climatic conditions.

It appears also that all the climate hazards affecting rain-fed sorghums also affect dry season sorghums; which reflects the strong dependence of dry season sorghum on meteoric water. On the other hand, the multiplicity of climate hazards affecting dry season sorghum can be explained by the diversity of the water resources (meteoric, surface, underground) essential to its production.

The adaptation strategies in use by sorghum farmers in the face of these climate hazards and water risks are summarized in Table 2.

The analysis of the nature of the adaptation strategies used by sorghum farmers in the face of climate hazards and water risks could lead to the following remarks:

- All the adaptation strategies used by sorghum farmers aim to compensate for either the poor distribution of rains, the droughts (meteorological, edaphic, hydrological, socioeconomic), or to both of the two types of constraints.

- An overwhelming majority of these adaptation strategies have been adopted to cope with meteorological drought, which is the main form of drought faced by sorghum farmers; it is followed by edaphic drought, then hydrological drought.

Table 2 Nature and frequency of adoption of the adaptation strategies used by sorghum farmers

\begin{tabular}{l|l|l|l|l}
\hline \multirow{2}{*}{ Adaptation strategies } & \multicolumn{2}{l}{ Rainy season sorghum } & \multicolumn{2}{l}{ Dry season sorghum } \\
\cline { 2 - 5 } & Total & $\mathbf{( \% )}$ & Total & $\mathbf{( \% )}$ \\
\hline Sowing early matured varieties & 131 & 43,67 & 175 & $\mathbf{5 8 , 3 3}$ \\
\hline Sowing or transplanting early & 178 & $\mathbf{5 9 , 3 3}$ & 139 & $\mathbf{4 6 , 3 3}$ \\
\hline Sowing of drought resistant crops varieties & 178 & $\mathbf{5 9 , 3 3}$ & 194 & $\mathbf{6 4 , 6 7}$ \\
\hline Diversification of crops varieties & 94 & 31,33 & 182 & $\mathbf{6 0 , 6 7}$ \\
\hline Changing of crops or crops' varieties & 105 & 35 & 25 & 08,33 \\
\hline Labor of plots and mounding of plants & 234 & $\mathbf{7 8}$ & 96 & 32 \\
\hline Temporary or permanent transfer of crops & 170 & $\mathbf{5 6 , 6 7}$ & 30 & 10 \\
\hline Making of racks or bunds & 103 & 34,33 & 203 & $\mathbf{6 7 , 6 7}$ \\
\hline Nursery organic or inorganic fertilizer input & 271 & $\mathbf{9 0 , 3 3}$ & 82 & 27,33 \\
\hline Diversification of income-generating activities & 195 & 65 & 141 & 47 \\
\hline Crops diversification & 268 & $\mathbf{8 9 , 3 3}$ & 272 & $\mathbf{9 0 , 6 7}$ \\
\hline Multiplication of weeding & 123 & 41 & 20 & 06,67 \\
\hline Sowing of molten seed holes or dried plants & 166 & $\mathbf{5 5 , 3 3}$ & 05 & 01,67 \\
\hline Rocky bunds & 05 & 01,67 & - & - \\
\hline Late transplanting & - & - & 125 & $\mathbf{4 1 , 6 7}$ \\
\hline Deepening piles & - & - & 129 & 43 \\
\hline Purchase or request of nurseries & - & - & 104 & 34,67 \\
\hline Scaling of nurseries over the time & - & - & 203 & $\mathbf{6 7 , 6 7}$ \\
\hline Organic or inorganic fertilization of nurseries & - & - & 107 & 35,67 \\
\hline Cleaning and deepening of ponds & - & - & 131 & $\mathbf{6 0 , 3 3}$ \\
\hline Water research over long distances & - & - & 95 & 31,67 \\
\hline Fertilization of transplanting water & - & - & 06 & 02 \\
\hline
\end{tabular}


- Despite the identification of floods as another main water risk by sorghum farmers, no adaptation strategy has apparently been adopted by them to deal with it.

- The adaptation strategies used are traditional in their majority, and those recognized as efficient such as the irrigation or the use of improved crops' varieties are almost unused.

- Despite the traditional nature of the adaptation strategies used, their adoption rates by farmers are low in the majority of cases.

The synthesis of these preceding remarks conducts to the following conclusions:

- The poor spatiotemporal distribution of rains and the drought (especially meteorological), constitute, respectively, the main climate hazard and the main water risk faced by farmers in the area; this has been previously confirmed by several researchers including Batterbury and Mortimore (2013), then Mortimore and Adams (2000), who consider that all the Sahelian farmers' problems correspond to a group of "five (5) crises of the Sahelian orthodoxy," to which they are trying to provide solutions, the main one of which is represented by drought.

- Sorghum farmers in particular and farmers in general from the region are very vulnerable because they do not really adapt to but they simply cope with the climate change; this confirms the observation made by the IPCC (2014), Sissoko et al. (2010), OECD (2010), then Leary et al. (2007), according to whom Sahelian farmers do not adapt to but simply cope with climate change; these sorghum farmers' maladaptation (lack of adaptation) can be perceived or explained from the previous paragraph 1 through the practice of selfconsumption agriculture, the small size of the sown areas, the low quantity of agricultural inputs used, the poor access to agricultural supervision and to credits, the multiplication of income-generating activities, and the weak school enrollment rate. Contrary to this result, authors like Jouve (2010) and Batterbury and Forsyth (1999) find that in fact Sahelian farmers adapt to climate change. This duality of contradictory observations could be justified either by the different use of the concept of adaptation, or by the difference in the results obtained in different contexts.

\section{Sahelian Farmers Adaptation Strategies' Typologies}

On the whole, the farmers' adaptation strategies in the dry regions (semiarid, arid) can be classified both on the basis of farmers' practices, which takes into account all the actions undertaken by them to ensure their survival, and on the basis of the agricultural research, which is only interested in crop management. According to these two angles of analysis, the typologies could be grouped into three main categories: 
- The first category of typologies, proposed by Nhemachena and Hassan (2007), Jouve (2010), Ngigi (2009), Diarra (2008), Fabre (2010), then Batterbury and Mortimore (2013).

- The second category of typologies brings together those proposed by Batterbury and Forsyth (1999), then Ngigi (2009).

- The third category of typologies, which corresponds to that proposed by Dingkuhn (2009).

\section{First Category of Typologies}

The first category of typologies is that proposed by Nhemachena and Hassan (2007), Jouve (2010), Ngigi (2009), Diarra (2008), Fabre (2010), then Batterbury and Mortimore (2013). These typologies distinguish adaptation strategies which consist of facing risks from those focusing on avoiding risks.

In general, Nhemachena and Hassan (2007) estimate that there are roughly two types of adaptation strategies in agricultural production systems:

1. The strategies which are based on "confronting water risks," essentially based on increasing diversification which corresponds to the adoption of production activities tolerant to drought and/or resistant to thermal stress, as well as activities that relate to efficient management that value the quantity of water available and ambient temperatures among other factors.

2. The strategies which are based on "eviction of water risks," essentially based on crop management practices, and which consist in avoiding that the critical stages of plant growth do not coincide with bad climatic conditions such as inter-season droughts (modification of the crop cycle and modification of sowing and harvest dates).

Jouve (2010), Ngigi (2009), and Diarra (2008), based on the subjective assessment of risks and vulnerability, have grouped the farmers' adaptation strategies into three (3) categories:

1. The "pre-risk" or preventive management options (prevention strategies) or before risks, such as the choice between risk-tolerant varieties, investment in water management, and diversification of survival and agriculture, well before the arrival of the growing season.

2. The "intra-season" adjustment of crops and resources management options in response to constantly changing specific climatic shocks, also called "adaptive methods" or "mitigation strategies"; these are peasant innovations put in place to adapt to climate change and to make the best use of rainwater resources.

3. The "post-risk" management options or "palliative methods" or "adjustment strategies," which minimize the impacts of adverse climate shocks; they seek to mitigate the effects of climatic risks which particularly affect poor rural 
populations; these methods, based on the establishment of insurance systems, aim to stabilize farmers' incomes and avoid their indebtedness and decapitalization during bad years; they are intended to alleviate the impact of the event when it happened.

The comparison between these two typologies indicates that they are identical: the strategies based on "confronting water risks" proposed by Nhemachena and Hassan (2007) correspond to the intra-season adjustment and post-risk" management options in the typology proposed by Jouve (2010), Ngigi (2009), and Diarra (2008), while "crowding out water risks" corresponds to "pre-risk" management options.

Batterbury and Mortimore (2013) estimate that the Sahelian farmers' adaptation strategies correspond to the five crises of Sahelian orthodoxy:

- The management of rainfall by farmers each year

- The integration of agriculture and animal husbandry

- The conservation management of biodiversity

- The intensive and sustainable soil management

- The diversification of livelihoods

Jouve (2010) and Fabre (2010), for their part, believe that sahelian farmers' adaptation strategies to climate variability can be split into three (3) groups:

- The choice of crops (species, varieties)

- The modification of practices (irrigation and drainage, polyculture, modification of the cropping calendar)

- The modification of sources of income (crafts, livestock, trade, etc.)

Reconciling the last two typologies also indicates that they are similar insofar as the management of rainfall, the integration of agriculture and animal husbandry, and the intensive and sustainable management of soil suggested by Batterbury and Mortimore (2013) corresponds to the modification of practices suggested by Jouve (2010) and Fabre (2010). Similarly, the conservation management of biodiversity corresponds to the choice of crops, while the diversification of livelihoods corresponds to the modification of sources of income.

Finally, the comparison between the two previous typologies and the two last ones indicates that they are in fact similar. The "increase in diversification" proposed by the first two typologies corresponds to the "modification of the sources of income and the practices" proposed by the two last ones, while the crop "management practices" correspond to the "choice of crops"; this amounts to saying that in terms of farmers' practices, the four typologies are identical.

The particularity of this first category of typologies is that they are based principally on the natural agro-pastoral resources (water, soils, crops, animals) spatiotemporal management. 


\section{Second Category of Typologies}

The second category of typologies includes those proposed by Batterbury and Forsyth (1999), then Ngigi (2009). These typologies distinguish "adaptive processes" which are long and medium terms adaptation strategies, from "adaptive strategies" which are short term actions intended to ensure the survival of farmers.

Batterbury and Forsyth (1999) find that farmers' adaptation strategies can be divided into two categories:

- The "adaptive processes," which generally call for a spatial extension of activities outside the locality, in order to reduce the pressure on local resources; it is an appropriate strategy for communities in dry regions where diversification is the main response to drought or crop failure; adaptation processes are long-term transitions that change the configuration of relationships between a community and its resources; each transition has several components, and adoption and the form that transition takes depends on several factors of change, such as farmers' knowledge, the biophysical environment (especially precipitation and soil), and availability of the work force; for this reason, each transition will be relatively unique, thus reflecting the interactions between farmers, their institutions, their economic policy, and their environment.

- The "adaptive strategies" are short-term practices, adopted in response to sudden shocks or difficulties in accessing resources.

Ngigi (2009) differentiate adaptation strategies to climate change between:

- "Adaptation itself" or "adaptation strategies," which constitutes a change in response to changing climatic parameters and

- "Coping mechanisms" or "coping strategies," generally in the short term.

The comparison between these two typologies shows that they are also similar. "Adaptation itself" corresponds to "adaptive processes," while "coping strategies" correspond to "adaptive strategies."

This category of typologies is characterized by the fact that tries to differentiate the farmers' adaptation strategies, either on the long- and medium-terms use of agricultural or nonagricultural strategies to truly adapt climate change, or on the short-term use of agricultural or nonagricultural strategies to cope with climate change (without really adapting to it); in other words, it differentiates farmers' adaptation strategies based on whether they are genuinely adapting in the long- to medium-terms, or whether they are simply coping in a short-term with climate change to just ensure their survival. 


\section{Third Category of Typologies}

The typology proposed by Dingkuhn (2009), corresponds to the third category, and groups adaptation strategies according to the agricultural research fields, into four very distinct types:

- Genetic adaptation (drought resistant varieties, early varieties)

- Agronomic adaptation (all the strategies linked to the management of crops, which are the most numerous)

- Geographic adaptation (temporary or permanent change in cultures)

- Temporal adaptation (early sowing, late sowing, staggering of nurseries)

The particularity of this category of typologies is that it is not interested in the climate hazards or risks that farmers are facing (first category of typologies), nor in the strength or weaknesses of the adaptation strategies in use (second category of typologies), but simply to the scientific field to which each of these adaptation strategies relates.

The comparison between all the previous typologies and the current one proposed by Dingkuhn (2009) indicates that one could very well transpose the genetic, agronomic, geographic, and temporal adaptations suggested by this typology in these ones; however, the socioeconomic adaptation taken into account by these typologies does not exist in the one proposed by Dingkuhn (2009), and this could be explained by the fact that this typology is essentially concerned with crop management and not with farmers practices in their whole.

After a careful analysis of the typologies' categories and the sorghum farmers' adaptation strategies, it appears that it is appropriate to characterize them on the basis of the first category of typologies because both (category of typologies, adaptation strategies) are oriented towards the agro-pastoral natural resources' management; on the other hand, while the second category of typologies requires the strategies to be monitored over time in order to assess their effectiveness, the third category is more descriptive and does not allow to grasp easily the real objectives targeted by sorghum farmers.

\section{Characterization of Sorghum Farmers' Adaptation Strategies}

The adaptation strategies were grouped according to crops, so first, the adequacy of the rainy season sorghum farmers' adaptation strategies has been tested using the KMO test. The results are listed in Table 3.

All the KMO values taken by the different adaptation strategies being greater than 0.49 , all these strategies have been used in the test. 
Table 3 Results of the KMO sample adequacy test applied to the rainy season sorghum farmers' adaptation strategies

\begin{tabular}{l|l|l}
\hline Adaptation strategies & Codes & KMO values \\
\hline Sowing early matured varieties & SEVARPRE & 0.834 \\
\hline Sowing or transplanting early & SEMISSEC & 0.743 \\
\hline Sowing of drought resistant crops varieties & SEMVARES & 0.817 \\
\hline Diversification of crops varieties & DIVARCUL & 0.896 \\
\hline Change of crops or crops varieties & CHASPVA & 0.671 \\
\hline Labor of plots and mounding of plants & LABBUTPL & 0.815 \\
\hline Temporary or permanent transfer of crops & MUTEDECU & 0.858 \\
\hline Making of racks & CONFCAS & 0.925 \\
\hline Organic fertilizer input & FUMORGA & 0.849 \\
\hline Diversification of income-generating activities & DIVACGER & 0.854 \\
\hline Crops' diversification & DIVERCUL & 0.850 \\
\hline Multiplication of weeding & MULTSARC & 0.867 \\
\hline Sowing of molten seed holes or dried plants & RESREPIQ & 0.845
\end{tabular}

The eigenvalues of the various factors from the PCA results reveal the existence of two (2) main factors, which explain 53.64\% ( $>49 \%$ ) of the total variation of the adaptation strategies, in accordance with the KMO rule (Fig. 2 and Table 4).

Loading these adaptation strategies according to the two main factors gave the results mentioned in Table 5.

Factor 1 brings together the adaptation strategies "sowing of early matured varieties," "diversification of crop varieties," "change of crops or crop varieties," "labor of plots and mounding of plants," "temporary or permanent transfer of crops," "organic or mineral fertilizer input," and "sowing of melted seed holes or dried plants." This factor can be called "Adaptation to climate hazards through efficient management of natural resources (soil, water, crops)." This factor can be interpreted as the decision-making by farmers to continue to carry out agricultural activities despite the risks, and corresponds in fact to the adaptation strategy by "confronting climate hazards and water risks" suggested by the first category of typologies.

Factor 2 groups together the adaptation strategies "sowing or transplanting early," "sowing of drought resistant crops varieties," "making of racks," "diversification of income-generating activities," "crop diversification," and "multiplication of weeding." This factor brings together adaptation strategies whose main objective is to avoid water risks.

It therefore corresponds to all the activities carried out by farmers with the aim of minimizing climate hazards and water risks and their impacts; and for that, it corresponds well to the adaptation strategy by "eviction or minimization a priori of climate hazards and water risks" suggested by the first category of typologies.

It finally emerges from this analysis that all the rainy season sorghum farmers' adaptation strategies correspond very well to the typology proposed by the first category of typologies' authors, namely adaptation by "confronting water risks" and adaptation by "a priori eviction or minimization of water risks". 


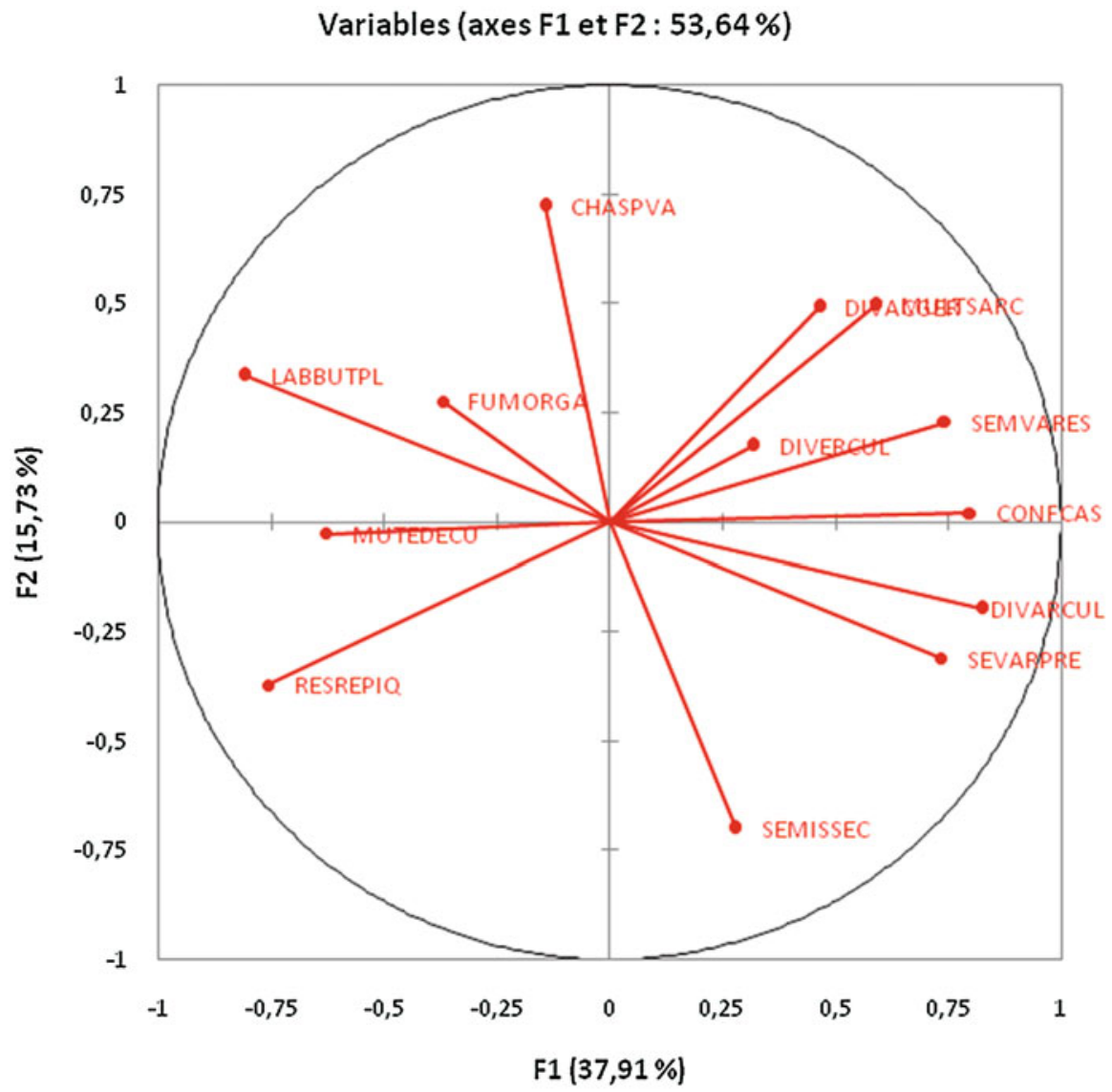

Fig. 2 Percentage explanations of variables by factors F1 and F2

Table 4 Variability explained by factor

\begin{tabular}{l|l|l|l}
\hline Factors & Variation & \% & Cumulative \% \\
\hline F1 & 4.928 & 37.908 & 37.908 \\
\hline F2 & 2.045 & 15.731 & $\mathbf{5 3 . 6 4}$ \\
\hline
\end{tabular}

The test of the adequacy of the dry season sorghum farmers' adaptation strategies using the KMO test gave the results mentioned in Table 6.

All the KMO values taken by the adaptation strategies are greater than 0.49 , except that of the "late transplanting" strategy, which will not be used in the KMO test.

The eigenvalues of the different factors from the PCA results reveal the existence of five (5) main factors, which explain $53.612 \%$ ( $>49 \%$ ) of the total variation of the adaptation strategies, in accordance with the KMO rule. (Fig. 3 and Table 7).

Loading the adaptation strategies of the dry season sorghum farmers according to the five (5) main factors gave the results mentioned in Table 8. 
Table 5 Results of the loading of the rainy season sorghum farmers' adaptation strategies by factor

\begin{tabular}{l|r|r}
\hline Adaptation strategies & Factor 1 & Factor 2 \\
\hline Sowing early matured varieties & $-\mathbf{0 . 5 7 0}$ & 0.067 \\
\hline Sowing or transplanting early & -0.444 & $\mathbf{- 0 . 5 1 1}$ \\
\hline Sowing of drought resistant crops varieties & -0.267 & $\mathbf{0 . 5 1 3}$ \\
\hline Diversification of crops varieties & $-\mathbf{0 . 7 1 2}$ & 0.292 \\
\hline Change of crops or crops varieties & $\mathbf{0 . 5 8 2}$ & 0.475 \\
\hline Ploughing of plots and mounding of plants & $\mathbf{0 . 8 6 2}$ & -0.217 \\
\hline Temporary or permanent transfer of crops & $\mathbf{0 . 5 4 0}$ & -0.424 \\
\hline Making of racks & -0.572 & $\mathbf{0 . 4 5 6}$ \\
\hline Organic or mineral fertilizer input & $\mathbf{0 . 5 5 4}$ & -0.052 \\
\hline Diversification of income-generating activities & -0.127 & $\mathbf{0 . 6 9 7}$ \\
\hline Crops' diversification & 0.133 & $\mathbf{0 . 1 6 3}$ \\
\hline Multiplication of weeding & -00.77 & $\mathbf{0 . 6 9 0}$ \\
\hline Sowing of melted seed holes or dried plants & $\mathbf{0 3 . 6 5}$ & -0.735
\end{tabular}

Table 6 Results of the KMO sample adequacy test applied to the dry season sorghum farmers' adaptation strategies

\begin{tabular}{l|l|c}
\hline Adaptation strategies & Codes & KMO values \\
\hline Sowing of early matured varieties & SEVARPRE & 0.817 \\
\hline Sowing or transplanting early & SEMISSEC & 0.577 \\
\hline Sowing of drought resistant crops varieties & SEMVARES & 0.743 \\
\hline Diversification of crops varieties & DIVARCUL & 0.782 \\
\hline Change of crops or crops varieties & CHASPVA & 0.522 \\
\hline Ploughing of plots and mounding of plants & LABBUTPL & 0.801 \\
\hline Temporary or permanent transfer of crops & MUTEDECU & 0.540 \\
\hline Making of racks or bunds & CONFCAS & 0.771 \\
\hline Crops organic or inorganic fertilizer input & FUMORGA & 0.773 \\
\hline Diversification of income-generating activities & DIVACGER & 0.731 \\
\hline Crops diversification & DIVERCUL & 0.500 \\
\hline Multiplication of weeding & MULTSARC & 0.687 \\
\hline Sowing of molten seed holes or dried plants & RESREPIQ & 0.621 \\
\hline Late transplanting & SREPITAR & 0,444 \\
\hline Deepening piles & APROFPI & 0.555 \\
\hline Purchase or request of nurseries & ACHATPE & 0.663 \\
\hline Scaling of nurseries over the time & ECHELPEP & 0.780 \\
\hline Organic or inorganic fertilization of nurseries & FEORMIPE & 0.568 \\
\hline Cleaning and deepening of ponds & CURAMAE & 0.753 \\
\hline Water research over long distances & RECHEAGD & 0.739 \\
\hline Fertilization of transplanting water & FERTEARE & 0.585 \\
\hline & &
\end{tabular}

Factor 1 groups together the adaptation strategies "sowing of early matured varieties", "sowing of drought-tolerant varieties", "diversification of crop varieties", "ploughing of plots and mounding of plants", "making of racks or bunds", and 


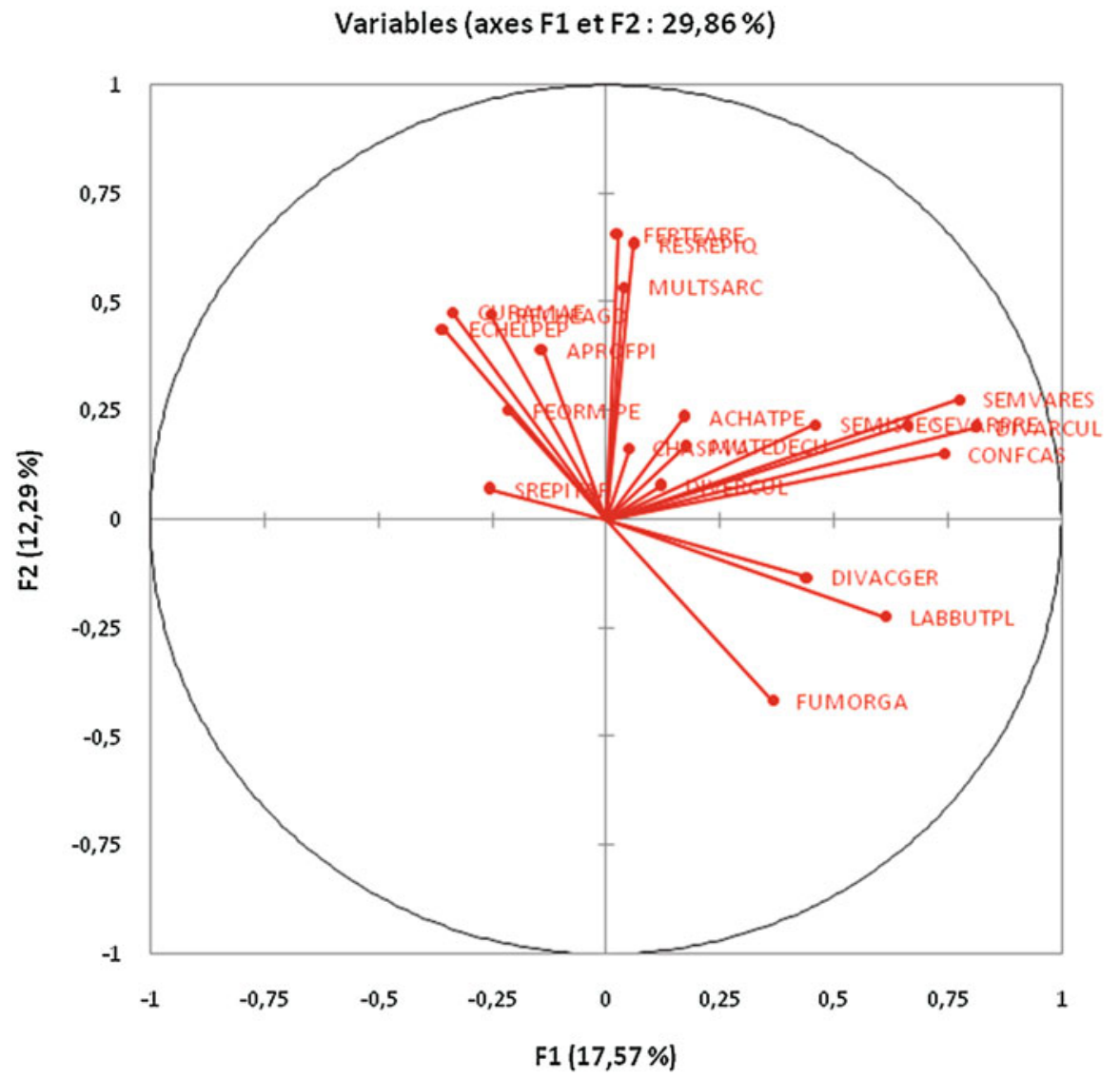

Fig. 3 Percentage of explanations of variables by factors F1 and F2

Table 7 Variability explained by factor

\begin{tabular}{l|l|l|l}
\hline Factors & Variation & $\%$ & Cumulative \% \\
\hline F1 & 3.690 & 17.571 & 17.571 \\
\hline F2 & 2.581 & 12.292 & 29.863 \\
\hline F3 & 2.132 & 10.151 & 40.014 \\
\hline F4 & 1.561 & 7.434 & 47.447 \\
\hline F5 & 1.295 & 6.165 & $\mathbf{5 3 . 6 1 2}$ \\
\hline
\end{tabular}

"diversification of income-generating activities". This factor brings together all of the farmers' adaptation strategies which aim to avoid or minimize water risks and their impacts, and in fact corresponds to the adaptation strategy by "a priori eviction or minimization of water risks" suggested by the first category of typologies.

Factor 2 groups together the adaptation strategies "multiplication of weeding", "sowing of melted seed holes or dried plants", "deepening of piles", "scaling of nurseries over the time", "cleaning and deepening of ponds", "water research over 
Table 8 Results of the loading of the dry season sorghum farmers' adaptation strategies by factor

\begin{tabular}{|c|c|c|c|c|c|}
\hline Adaptation strategies & $\begin{array}{l}\text { Factor } \\
1\end{array}$ & $\begin{array}{l}\text { Factor } \\
2\end{array}$ & $\begin{array}{l}\text { Factor } \\
3\end{array}$ & $\begin{array}{l}\text { Factor } \\
4\end{array}$ & $\begin{array}{l}\text { Factor } \\
5\end{array}$ \\
\hline Sowing of early matured varieties & 0.663 & 0.219 & -0.100 & 0.194 & 0.149 \\
\hline Sowing or transplanting early & 0.459 & 0.219 & -0.168 & -0.163 & 0.596 \\
\hline $\begin{array}{l}\text { Sowing of drought resistant crops } \\
\text { varieties }\end{array}$ & 0.777 & 0.277 & -0.307 & 0.124 & -0.240 \\
\hline Diversification of crops varieties & 0.813 & 0.213 & -0.246 & 0.075 & -0.160 \\
\hline Change of crops or crops varieties & 0.052 & 0.165 & -0.052 & 0.487 & -0.248 \\
\hline $\begin{array}{l}\text { Ploughing of plots and mounding of } \\
\text { plants }\end{array}$ & 0.613 & -0.224 & 0.352 & -0.070 & -0.107 \\
\hline $\begin{array}{l}\text { Temporary or permanent transfer of } \\
\text { crops }\end{array}$ & 0.176 & 0.170 & 0.243 & -0.035 & -0.391 \\
\hline Making of racks or bunds & 0.743 & 0.152 & -0.349 & 0.055 & -0.171 \\
\hline $\begin{array}{l}\text { Crops organic or inorganic fertilizer } \\
\text { input }\end{array}$ & 0.367 & -0.416 & 0.445 & 0.029 & 0.140 \\
\hline $\begin{array}{l}\text { Diversification of income-generating } \\
\text { activities }\end{array}$ & 0.443 & -0.133 & 0.428 & 0.158 & 0.387 \\
\hline Crops diversification & 0.120 & 0.077 & -0.220 & -0.222 & 0.194 \\
\hline Multiplication of weeding & 0.039 & 0.535 & 0.410 & -0.154 & -0.272 \\
\hline $\begin{array}{l}\text { Sowing of melted seed holes or dried } \\
\text { plants }\end{array}$ & 0.061 & 0.633 & 0.464 & -0.312 & 0.019 \\
\hline Deepening of piles & -0.139 & 0.392 & -0.287 & 0.033 & 0.222 \\
\hline Purchase or request of nurseries & 0.172 & 0.236 & 0.245 & 0.469 & 0.297 \\
\hline Scaling of nurseries over the time & -0.357 & 0.438 & -0.386 & -0.007 & 0.084 \\
\hline $\begin{array}{l}\text { Organic or mineral fertilization of } \\
\text { nurseries }\end{array}$ & -0.215 & 0.253 & 0.262 & 0.418 & 0.245 \\
\hline Cleaning and deepening of ponds & -0.337 & 0.477 & -0.359 & -0.023 & -0.038 \\
\hline Water research over long distances & -0.251 & 0.471 & 0.049 & 0.389 & 0.143 \\
\hline Fertilization of transplanting water & 0.026 & 0.657 & 0.498 & -0.401 & -0.016 \\
\hline
\end{tabular}

long distances", and "fertilization of transplanting water". This factor brings together all the adaptation strategies aimed at the sustainable management of water resources, and can be called "Adaptation to water risks by efficient management of water resources".

Factor 3 contains the "crops organic or inorganic fertilizer input" strategy. It brings together strategies aimed at sustainable soil management, and can be called "Adaptation to water risks through efficient soil management".

Factor 4 groups together the strategies "change of crops or crop varieties", "crops diversification", "purchase or request of nurseries", and "organic or mineral fertilization of nurseries". It brings together strategies aimed at the sustainable management of crops, and can be called "Adaptation to water risks through sustainable management of crops".

Factor 5 groups together the strategies "sowing or transplanting early" and "temporary or permanent transfer of crops", which aim to avoid water risks, and can be called "Adaptation by a priori eviction of water risks". 
Analysis of all the five factors reveals that factors 1 and 5 correspond to the farmers' adaptation to climate change by "eviction or a priori minimization of water risks", while factors 2, 3, and 4 correspond to their adaptation by "confronting water risks"; and therefore, it could be said that the dry season sorghum farmers' adaptation strategies corresponds very well to the typology proposed by the authors of the first category of typologies, namely, adaptation by "confrontation with the water risks" and adaptation by "a priori eviction or minimization of the water risks."

That said, depending on the results of the characterization of the sorghum farmers' adaptation strategies using PCA and KMO test, their whole adaptation process can be explained through a set of two actions:

1. The agro-pastoral natural resources management by "confrontation with the climate hazards and water risks" or by "eviction of the climate hazards and water risks".

2. The intense spatiotemporal diversification of the practices (agro-pastoral natural resources management, income generating activities).

Finally, it can be said that the characterization of the sorghum farmers' adaptation strategies shows that they are more complex than most authors who have established the typologies thought, because of the spatiotemporal diversification of the practices.

\section{Conclusion}

At the end of this chapter, we could draw the following conclusions:

- The poor spatiotemporal distribution of rains and the drought respectively constitute the main climate hazard and the main water risk faced by sorghum farmers in particular, and farmers in general in the semi-arid region of Cameroon.

- The sorghum farmers are highly vulnerable to climate change, and that could be perceived through the coexistence of all the three forms of drought (meteorological, agricultural, hydrological), the permanent food insecurity, the mostly traditional adaptation strategies used and their very low adoption rates, the underuse or absence of efficient adaptation strategies (irrigation, improved crop varieties), and their socioeconomic characteristics (the practice of self-consumption agriculture, the small size of the sown areas, the low quantity of agricultural inputs used, the poor access to agricultural extension and to credits, the multiplication of incomegenerating activities, and the weak school enrollment rate).

- The characterization of the adaptation strategies used shows that they are more complex than most authors who have established the typologies thought because the whole adaptation process used by sorghum farmers can be explained through a set of two actions: the agro-pastoral natural resources management by "confrontation with the climate hazards and water risks" or by "eviction of the climate hazards and water risks"; and the intense spatiotemporal diversification of the 
practices (agro-pastoral natural resources management, income generating activities).

- Insofar, as the farmers are very vulnerable to the climate change, it seems given their poor socioeconomic conditions that a real improvement in their resilience depends absolutely on a real and deep improvement of these socioeconomic conditions.

\section{References}

Agossou DSM, Tossou CR, Vissoh VP, Agbossou KE (2012) Perception des perturbations climatiques, savoirs locaux et stratégies d'adaptation des producteurs agricoles béninois. Afr Crop Sci J 20(2):565-588

Arodokoun UA (2011) Socioeconomic impact of the use of NICTs in adaptation strategies to climate change in rural areas: the case of cotton farmers in Center-Benin. Thesis for the Diploma of Agricultural Engineer, University of Abomey-Calavi, Abomey

Batterbury SPJ, Forsyth T (1999) Fighting back: human adaptations in marginal environments. Environment 41(11):25-29

Batterbury SPJ, Mortimore MJ (2013) Adapting to drought in the west African Sahel. In: Boultner S, Palutikov J, Karoly D, Guitart D (eds) Symposium on natural disasters and adaptation to climate change. Cambridge University Press, Cambridge

Blanc E (2012) The impact of climate change on crop yields in sub-Saharan Africa. Am J Clim Chang 1:1-13

Borton J, Nicholds N (1994) Drought and Famine. London, England: FAO

CEDC (2010) Regional master plan for land management and use planning. Technical report. MINPLADAT, Yaoundé

Chédé F (2012) Vulnérabilité et stratégies d'adaptation au changement climatique des paysans du Département des Collines au Bénin: cas de la Commune de Savè. Mémoire de fin d'études pour l'obtention du diplôme de Mastère en Changement climatique et développement durable. Centre Regional AGRHYMET de Niamey, Niger

Diarra A (2008) Adaptation of Sahelian agriculture to climate change: an approach using stochastic modeling. Results of research presented at meetings of the International Institute for Water and Environment Engineering, Ouagadougou

Dingkuhn M (2009) Adaptation des plantes cultivées au changement climatique. In: Caron P (ed) Changement climatique et agriculture: l'environnement et la sécurité alimentaire en jeu. CIRAD, Paris

Fabre C (2010) The adaptation of food farmers in Senegal to climate change: the case of the rural community of Sessène, Thiès region. Master thesis in Geography, University of Montreal, Montreal

FAO (2009) Food production: the determining role of water. Food and Agriculture Organization of the United Nations (FAO), Rome

FAO, NDMC (2008) A review of drought occurrence and monitoring and planning activities in the Near East Region. FAO, Rome

Gnanglé PC, Egah J, Baco MN, Gbemavo CDSJ, Kakai RG, Sokpon N (2012) Perceptions locales du changement climatique et mesures d'adaptation dans la gestion des parcs à karité au Nord-Benin. Int J Biol Chem Sci 6(1):136-149

IPCC (2014) Climate change 2014 Synthesis report: headline statements from the summary for policymakers. Technical report. IPCC, Geneva

Jouve P (2010) Practices and strategies for adapting farmers to climatic hazards in sub-Saharan Africa. Grain de sel 49:15-16

L'Hôte Y (2000) Climatology. In: Seignobos C, Iyébi-Mandjeck O (eds) Atlas of the province of far North Cameroon (Plate 2). IRD, Paris 
Leary N, Kulkarmi J, Seipt C (2007) Assessments of impacts and adaptation to climate change: summary of the final report of the AIACC project. Technical report. START, Washington, DC

Mortimore MJ, Adams WM (2000) Farmer adaptation, change and crisis in the Sahel. Glob Environ Chang 11:49-57

Ngigi NS (2009) Climate change adaptation strategies: water resources management options for smallholder farming systems in sub-Saharan Africa. Synthesis report. MDG Centre for East and Southern Africa, Nairobi

Nhemachena C, Hassan R (2007) Micro-level analysis of farmers' adaptation to climate change in southern Africa. IFPRI discussion paper 00714. IFPRI, Washington, DC

OECD (2010) Gestion durable des ressources en eau dans le secteur agricole. OCDE, Paris

Sissoko K, Van Keulen H, Verhagen J, Tekken V, Battaglini A (2010) Agriculture, livelihoods and climate change in the West African Sahel. Reg Environ Change 3:25-37

Yesuf M, Di Falco S, Deressa T, Ringler C, Kohlin G (2008) The impact of climate change and adaptation on food production in low-income countries: evidence from the Nile Basin (Ethiopia). IFPRI discussion paper 00828. IFPRI, Addis Ababa

Open Access This chapter is licensed under the terms of the Creative Commons Attribution 4.0 International License (http://creativecommons.org/licenses/by/4.0/), which permits use, sharing, adaptation, distribution and reproduction in any medium or format, as long as you give appropriate credit to the original author(s) and the source, provide a link to the Creative Commons license and indicate if changes were made.

The images or other third party material in this chapter are included in the chapter's Creative Commons license, unless indicated otherwise in a credit line to the material. If material is not included in the chapter's Creative Commons license and your intended use is not permitted by statutory regulation or exceeds the permitted use, you will need to obtain permission directly from the copyright holder.

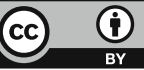

